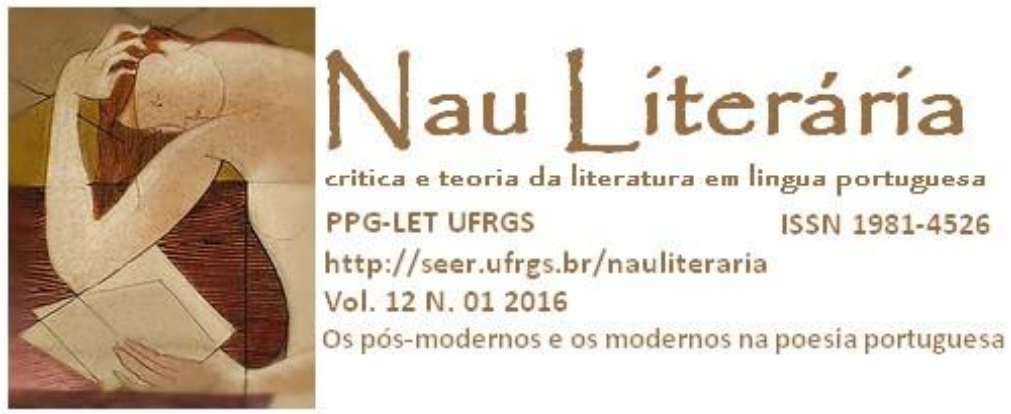

\title{
DA IMAGEM PICTÓRICA À IMAGEM POÉTICA: \\ “PARA JULIUS BISSIER", DE ANTÓNIO RAMOS ROSA
}

\section{FROM PICTORIAL IMAGE TO POETIC IMAGERY: "PARA JULIUS BISSIER", BY ANTÓNIO RAMOS ROSA}

\author{
Natália Ubirajara Silva ${ }^{1}$
}

\begin{abstract}
RESUMO: O presente estudo aborda o processo de construção da imagem na poética de António Ramos Rosa. A partir do poema "Para Julius Bissier", que integra o livro Do domínio plástico (2004), verifica-se de que forma o poeta transita entre o universo das artes plásticas e o da poesia, vinculando o traço do pincel à palavra. $\mathrm{O}$ diálogo entre a produção de Bissier e a obra de António Ramos Rosa questiona a arte enquanto representação e propõe a imagem como cerne da criação artística.
\end{abstract}

PALAVRAS-CHAVE: António Ramos Rosa; Julius Bissier; intertextualidade; imagem.

\begin{abstract}
This study examines the process of construction of imagery in António Ramos Rosa's poetry. Starting from the poem "Para Julius Bissier", which is part of the book Do domínio plástico (2004), it is observed how the poet moves between the universes of plastic arts and poetry, linking the brush trace to the word. The dialog between Bissier's production and António Ramos Rosa's work questions art as representation and proposes image as the core of artistic creation.
\end{abstract}

KEYWORDS: António Ramos Rosa; Julius Bissier; intertext; image.

António Ramos Rosa (1924-2013) tem sido um dos principais nomes da cultura portuguesa contemporânea. Poeta, ensaísta, desenhista e tradutor, publicou mais de 50 obras entre 1958 e 2012. Em seus primeiros trabalhos, Ramos Rosa vinculou-se à estética neorrealista e ao surrealismo; logo, porém, passou a seguir uma vereda própria, sem filiações a correntes estilísticas. Nesse estilo próprio, sobressaem a obsessão pela origem - “o

\footnotetext{
${ }^{1}$ Doutora em Literaturas Portuguesa e Luso-africanas pela Universidade Federal do Rio Grande do Sul (UFRGS).
} 
imperativo de recuperar a "voz inicial'”' (CRUZ, 2005, p. 29) -, a busca pela perfeição estética e obras com “dimensão conceptual” (MEXIA, 2005, p. 56).

O livro Do domínio plástico (2004) traz uma seleção de poemas ramos-rosianos vinculados às artes plásticas. A viúva do poeta, Agripina Costa Marques, selecionou textos inéditos e outros já publicados em livros de poesia e em catálogos de exposição. Fundamentado no diálogo com obras de diversos $\operatorname{artistas}^{2}$, Do domínio plástico é um exemplo da pós-moderna e "fértil ampliação da fronteira entre as artes literárias e visuais" (HUTCHEON, 1991, p. 26). Em cada poema, conjugam-se elementos próprios da poética de Rosa e da estética do artista plástico cuja obra é tematizada. O sujeito lírico, como que diante dos quadros, põe-se a expressar em palavras aquilo que parece indizível: o mundo da imagem pictórica. Paradoxalmente, as pinturas são "palavra e silêncio da palavra" (ROSA, 2004, p. 15), como lemos em 'Proposições sobre um fragmento de 'Le domaine enchanté' de Magritte", poema que abre o livro e que é considerado a arte poética de Ramos Rosa (cf. JÚDICE, 2005, p. 36).

Para melhor analisarmos a construção da imagem poética por meio do intertexto com as artes plásticas em Do domínio plástico, selecionamos o poema inédito "Para Julius Bissier" (ROSA, 2004, p. 49) $)^{3}$ :

\section{PARA JULIUS BISSIER}

$\begin{array}{lll}1 & \text { Os objectos libertam-se no espaço } & 10(6,10) \\ 2 & \text { do silêncio Não têm voz mas neles há uma música } & 13(3,7,13) \\ 3 & \text { do imponderável São talvez folhas frutos vasos } & 13(4,9,11,13) \\ 4 & \text { de uma delicadeza oblíqua de uma serenidade } & 15(8,15) \\ 5 & \text { imóvel e ligeira Se aqui há gravidade } & 13(6,13) \\ 6 & \text { ela é minúscula precária preciosa } & 12(4,8,12) \\ 7 & \text { Já nada é do mundo a subtil caligrafia } & 12(5,12) \\ 8 & \text { nas leves relações que graciosas respondem } & 12(6,12) \\ 9 & \text { ou não respondem Símbolos da natureza pura } & 14(4,6,14) \\ 10 & \text { da arte No seu alento breve } & 8(1,8) \\ 11 & \text { nada é mensagem tudo é júbilo gráfico } & 11(1,4,6,11) \\ 12 & \text { vegetal rigor musical oscilação } & 12(6,12) \\ 13 & \text { Entre o símbolo e o objecto desenha-se uma flor } & 13(3,6,13) \\ 14 & \text { e o que vemos não é a flor mas as linhas do vazio } & 14(6,14) \\ 15 & \text { que tranquilas inauguram as felizes miniaturas } & 15(7,15)\end{array}$

\footnotetext{
${ }^{2}$ A saber: Magritte, Vieira da Silva, Miró, Menez, Sónia Delaunay, Klee, Tàpies, Julio, Vespeira, Manuel Baptista, Braque, Götz, Atlan, Antonio Seguí, Mimi Fogt, Raquel Oliveira, Emerenciano, António Sampaio, Fátima Ramalho, Laura Cesana, Rui D’Oliveira, Julius Bissier, Maria José Oliveira e Laranjeira Santos

${ }^{3}$ Embora no título do poema e no índice de Do domínio plástico a grafia utilizada seja "Julus", o nome correto do pintor é Julius Bissier. Erro gráfico ou não, optamos por grafar "Julius" na transcrição do poema.
} 
O poema, organizado em uma única estrofe, apresenta 15 versos livres com número variável de sílabas poéticas. Chama a atenção, porém, o uso do decassílabo heroico (v. 1) e do verso alexandrino (v. 7, 8 e 12). A regularidade do acento tônico garante cadência ao poema. As aliterações também imprimem ritmo (repetição de /s/, encontros consonantais /pr/ e /gr/), bem como as assonâncias (repetição de /u/).

Conforme Paz, o ritmo "es sentido y dice algo" (1972, p. 58); o poema está fundado no ritmo (1972, p. 56). Ainda segundo o teórico e poeta, "el ritmo provoca una expectación, suscita un anhelar. Si se interrumpe, sentimos um choque" (1972, p. 57). No poema de Rosa, ocorre essa quebra da regularidade do ritmo no décimo verso: com sete sílabas, é o único com menos de dez sílabas poéticas em todo o texto. No próprio metro está representado o sentido do verso, que salienta o "alento breve" de um possuidor indeterminado (a sutil caligrafia? Símbolos?).

Goldstein (1991) assinala que, no texto poético, "a seleção e a combinação de palavras se fazem muitas vezes por parentesco sonoro" (1991, p. 5). Todorov aponta como elemento próprio da poesia o desvio paronímico (TODOROV, 1980, p. 72): no poema, o parentesco sonoro se torna semântico. Essa percepção vem ao encontro da teoria de Lotman (1978), segundo a qual os vocábulos que apresentam rimas e/ou são acentuados tonicamente têm seus sentidos interligados numa rede de equivalências. Essas redes formam arquissemas, unidades de sentido que incluem todos os elementos comuns (LOTMAN, 1978, p. 251). Em "Para Julius Bissier", agrupamos palavras e sintagmas nos arquissemas abaixo, cada qual construindo as imagens norteadoras do poema.

O primeiro arquissema, a que chamamos de "Palavra e silêncio da palavra" (cf. ROSA, 2004, p. 15), é constituído pelo seguinte grupo de palavras: silêncio (v. 1); ausência de voz (v. 2); serenidade imóvel (v. 4-5) gravidade (v. 5); não respondem (v. 9); mensagem (v. 11); linhas do vazio (v. 14). O segundo arquissema formado a partir dos acentos tônicos é o arquissema "Mundo dos objetos / realidade". Nele, agrupamos as palavras objetos (v. 1); folhas (v. 3); frutos (v. 3); vasos (v. 3); objeto (v.13); flor (v. 13-14); miniaturas (v. 15). No terceiro arquissema, "Criação", reunimos arte (v. 10), júbilo gráfico (v. 11) e símbolo (v. 13). O quarto e último arquissema é "Leveza e oscilação", vinculando as seguintes expressões: música do imponderável (v. 2-3); delicadeza oblíqua (v. 4); serenidade ligeira (v. 4-5); leves relações (v. 8); graciosas (v. 8); respondem ou não respondem (v. 8-9); alento breve (v. 10); musical oscilação (v. 12); tranquilas (v. 15); felizes miniaturas (v. 15). A divisão em arquissemas permite que vejamos quais são os temas e imagens do poema de Ramos Rosa: 
palavra e silêncio; objetos (mundo); criação artística; leveza e oscilação. Esses arquissemas dialogam intertextualmente com a obra do artista plástico Julius Bissier.

A intertextualidade "desempenha função constitutiva" (TODOROV, 1980, p. 61) em "Para Julius Bissier", bem como nos outros poemas de Do domínio plástico. Na primeira leitura, já se torna claro ao leitor que "something is missing from the text: gaps that need to be filled, references to an as yet unknown referent" (RIFFATERRE, 1990, p. 57). O primeiro índice da existência de sentidos indiretos calcados na intertextualidade é o título (cf. TODOROV, 1980, p. 30). Dedicar o poema a Julius Bissier não apenas homenageia o referente, mas dirige o leitor à investigação acerca de sua identidade e de sua produção artística. Segundo Todorov, esta é uma "evocação fortemente determinada" (1980, p. 76), controlada estritamente: "se o poema é obscuro é porque existe um saber determinado que o leitor não possui; desde que se lhe acrescente esse saber, a via da compreensão está aberta (não é, bem entendido, senão um começo)" (TODOROV, 1980, p. 78).

Sem pesquisar dados relativos a Julius Bissier, a leitura do poema de Ramos Rosa será limitada. Vemos, pois, que a menção a esse nome não é uma mera homenagem: a figura de Bissier é uma das imagens que o sujeito lírico constrói em seu poema, tendo importância interpretativa. É um caso de referencialidade intertextual específica (HUTCHEON, 1991, p. 200), expediente próprio da pós-modernidade. O intertexto é "emotionally and politically charged; the object of an act of influence" (WORTON; STILL, 1990, p. 2).

Julius Heinrich Bissier foi um pintor alemão ${ }^{4}$. Nascido em Freiburg im Breisgau no ano de 1893, frequentou a Universidade de Freiburg e a Escola de Arte Karlsruhe entre 1913 e 1914, mas interrompeu os estudos ao ser convocado para o serviço militar. Após a Primeira Guerra Mundial, continuou a se dedicar à pintura como autodidata. Nos seus primeiros trabalhos, na década de 1920, Bissier ligava-se à estética da Neue Sachlichkeit (Nova Objetividade) e ao Surrealismo. Depois de travar conhecimento com o pintor Willi Baumeister, sua obra passou por uma transição gradual para a pintura abstrata, não figurativa.

No fim da década de 1920, Bissier foi admitido como professor de desenho na Universidade de Freiburg. Um incêndio na universidade, em 1934, causou a destruição de grande parte dos trabalhos iniciais do artista. Nesse mesmo período, a pressão do governo nazista fez com que Bissier parasse de lecionar, dedicando-se à pintura e à criação de moldes para tapeçaria e tecelagem. Em meados dos anos 50, o artista desenvolveu uma técnica de

\footnotetext{
${ }^{4}$ A biografia de Julius Bissier aqui apresentada reúne dados coletados nas páginas <http://www.juliusbissier.com>, <http://www.tate.org.uk/art/artists/julius-bissier-756> e <http://eye-likey.blogspot.com.br/2012/01/ julius-bissier.html $>$.
} 
monotipia com têmpera ovo-e-óleo ${ }^{5}$, produzindo uma série de pinturas conhecidas como "miniaturas":

he [Bissier] developed a technique of egg-and-oil tempera that allowed him to use several washes on the canvas while retaining coloured contours to define his forms.

He called these small pictures 'miniatures', but they might also be referred to as microcosms, because of the wealth of their symbolism. ${ }^{6}$

Após mudar-se para Ascona, na Suíça, Bissier continuou a pintar, participando de diversas exposições e granjeando vários prêmios e menções honrosas. O pintor veio a falecer em 1965.

Nas miniaturas abaixo (Fig. 1 e Fig. 2), podem-se verificar alguns dos traços apontados por Ramos Rosa em seu poema.

Figura 1 - Rondine, 1961, têmpera ovo e óleo, 17 cm x 24 cm.

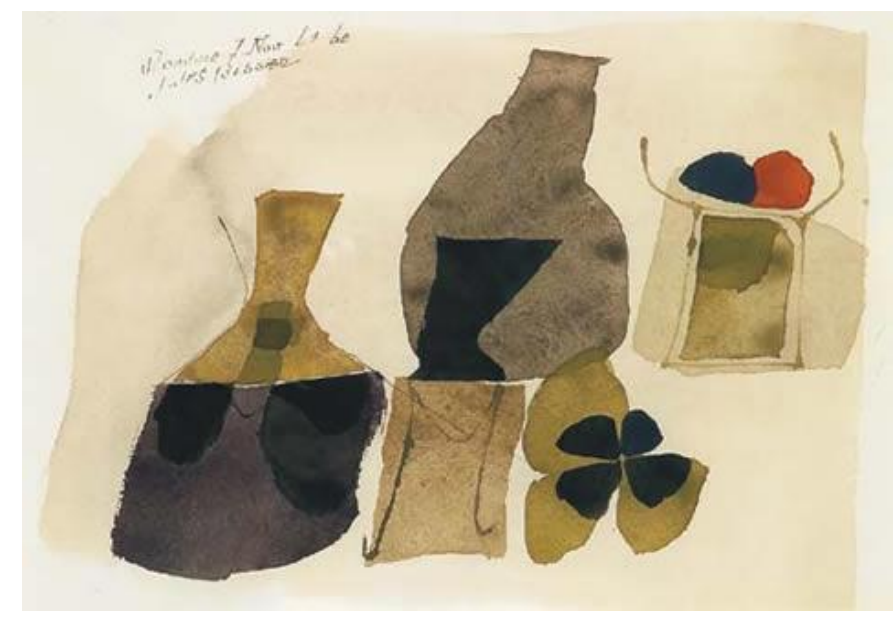

Fonte: 〈http://www.non-solo-arte.com/julius-bissier-watercolors.html>

Figura 2 -Composição 9, 1960, têmpera ovo e óleo, 18,3 cm x 23,7 cm.

\footnotetext{
${ }^{5}$ Essa técnica consiste na adição de óleo e gema de ovo à têmpera, garantindo outra plasticidade à tinta. $\mathrm{O}$ resultado obtido é um efeito de transparência.

${ }^{6}$ Disponível em: <http://eye-likey.blogspot.com.br/2012/01/julius-bissier.html>.
} 


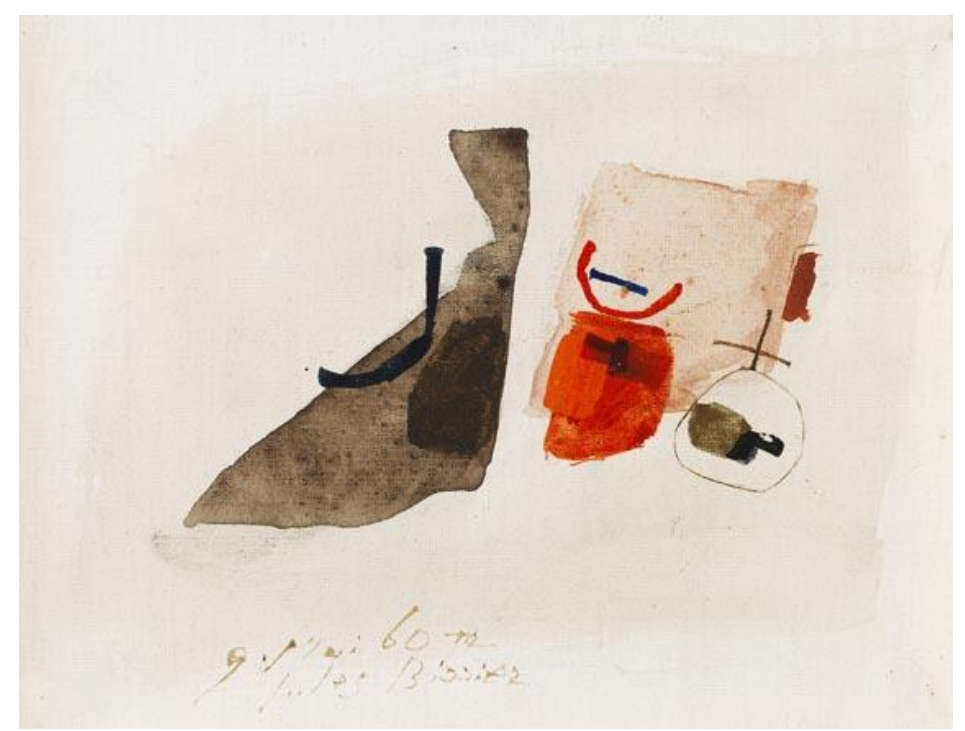

Fonte: <http://www.kettererkunst.com/details-e.php?obnr=111001620\&anummer=380>

As miniaturas, não figurativas, apresentam transparência, leveza e serenidade (não há cores e formas agressivas) e silêncio (as formas surgem no vazio). Os objetos se libertam e oscilam completamente soltos no espaço da tela. À semelhança desses objetos livres nas telas de Bissier (v. 1), os sintagmas do poema ramos-rosiano estão em liberdade. A estrutura "é sempre um fenômeno de sentido" (LOTMAN, 1978, p. 209): folhas, frutos, vasos libertos nos monotipos encontram-se soltos no poema, sem sinais de pontuação; a linguagem oscila. $\mathrm{O}$ poema de Rosa corporifica a afirmação de Paz: "es innecesaria la pontuación. Sobran las comas y los puntos: el poema es um flujo y reflujo rítmico de palabras” (1972, p. 72). Com o rompimento da sintaxe usual, o sentido fica indeterminado nos versos 14 e 15: o sujeito do verbo "inauguram" (v. 15) é "as linhas tranquilas do vazio" ou "as felizes miniaturas"? Quem é sujeito e quem é objeto? No $12^{\circ}$ verso, há mais de uma possibilidade de unir os sintagmas apresentados: "vegetal rigor musical oscilação". A oscilação, a dúvida e a ambiguidade são reforçadas pelo uso do advérbio "talvez" (v. 3), pela conjunção alternativa "ou” (v. 9) e pelas palavras que integram o arquissema "Leveza e oscilação".

Contemplando as miniaturas, vemos como os sintagmas libertos no espaço do poema dialogam intertextualmente com a obra de Bissier: as indeterminações de sentido produzidas pela subversão da sintaxe e pelos enjambements expressam os sentidos indeterminados dos objetos oscilantes nos monotipos bissierianos, que não reproduzem modelos reais. O poema reproduz essa indeterminação, pois, devido ao afrouxamento da sintaxe, múltiplas interpretações são possíveis: “Cada imagen - o cada poema hecho de imágenes - contiene 
muchos significados contrarios o dispares, a los que abarca o reconcilia sin suprimirlos" (PAZ, 1972, p. 98).

Os versos de "Para Julius Bissier" podem ser agrupados em três blocos distintos (versos 1 a 6, 7 a 12 e 13 a 15), cada um deles destacando um aspecto da pintura de Bissier; mais especificamente, de suas miniaturas, como indica o último verso ("felizes miniaturas", v. 15). Nos versos de 1 a 6, centrados no campo dos objetos, o sujeito lírico descreve o que Bissier pinta em sua tela - folhas, frutos, vasos - e salienta a coexistência paradoxal entre silêncio e música, "equilíbrio instável” (BESSE, 1981, p. 36) característico da poética de Ramos Rosa.

Existem diversos poemas ramos-rosianos divididos nos polos música e silêncio: “A música começa / no deserto do não" (ROSA apud JÚDICE, 2005, p. 33). O silêncio é uma imagem que, segundo Júdice, remete à ingenuidade, à pureza do signo; a música se relaciona ao princípio rítmico da poesia (cf. JÚDICE, 2005, p. 33). Os poemas ramos-rosianos são criações que articulam os opostos e fundem esses dois elementos antinômicos (cf. CARLOS, 1988, p. 98-99). Para Ramos Rosa, a pintura bissieriana tem essa mesma característica, unindo o silêncio (v. 2) à música do imponderável (v. 2-3). Essa oposição é construída no poema por meio do arquissema "Palavra e silêncio da palavra".

Segundo Paz, "La imagen dice lo indecible: [...] la imagen puede decir lo que, por naturaleza, el lenguaje parece incapaz de decir" (1972, p. 106). As miniaturas de Bissier não têm voz (v. 2), mas nelas há a música do imponderável; nessa pintura nada é mensagem e tudo é júbilo gráfico, concordando com a ideia de que a imagem simplesmente é, e o sentido é um querer dizer (cf. PAZ, 1972, p. 109). Os trabalhos de Bissier fogem a explicações. Daí advém o silêncio (v. 2): apenas a imagem pode dizer o que quer dizer; ela explica a si mesma (cf. PAZ, 1972, p. 110). O paradoxo que se coloca é que, ao poetizar a obra de Bissier, Ramos Rosa consegue traduzir o intraduzível, convertendo as imagens pictóricas para o contexto verbal sem meramente explicá-las. O poeta traduz a representação do imponderável para a escrita mantendo a oscilação e a indeterminação dos sentidos.

Na segunda parte do poema (v. 7 a 12), o sujeito lírico tematiza os possíveis sentidos expressos na obra de Bissier; estamos, agora, no campo dos símbolos e da mensagem (ou, ainda, ausência de mensagem). A arte de Bissier não é figurativa, mas também não cria um mundo caótico. Se observarmos as figuras 1 e 2, perceberemos leveza e serenidade devido à técnica de pintura e às cores utilizadas pelo artista. Não há gravidade ou circunspecção, mas delicadeza e traços sutis do pincel. A fim de corresponder a essa imagem pictórica e construir 
o retrato verbal do estilo do pintor, Ramos Rosa constrói imagens de felicidade e harmonia, conforme se verifica no arquissema "Leveza e oscilação".

Os versos que ocupam graficamente a posição central - versos 7, 8 e 9 -, são também centrais na interpretação do poema. Ao referir-se aos traços do pincel como "caligrafia", Ramos Rosa não apenas se refere aos elementos de caligrafia que podem ser vistos na figura $2^{7}$, mas também aproxima o fazer artístico do pintor e do poeta. A caligrafia sutil do pincel de Bissier, bem como a do poeta, "já nada [são] do mundo" (v. 7); como diz Paz, "La palabra no es idéntica a la realidad que nombra" (1972, p. 35). As miniaturas não são figurativas, ou seja, não trazem uma mensagem (v. 11); elas se libertam no silêncio, símbolos da natureza pura da arte (v. 9-10). Segundo Paz, "purificar el lenguaje, tarea del poeta, significa devolverle su naturaleza original” (PAZ, 1972, p. 47). Bissier busca, com sua pintura, devolver à arte sua natureza pura por meio de obras em que "tudo é júbilo gráfico" (v. 11), numa "subtil caligrafia" (v. 7) em que os sentidos são dados por outros meios que não a figuração.

A arte não figurativa de Julius Bissier é uma tomada de posição quanto à criação artística e à possibilidade (ou impossibilidade?) de representação do real; "mas não te pintei a ti pintei a tua magia", diz-nos o sujeito lírico de "Do pintor ao seu modelo", outro dos poemas de Do domínio plástico (ROSA, 2004, p. 54). Sem representar a natureza tal qual ela é, o artista revela que sua obra apresenta um sentido indireto, simbólico (cf. TODOROV, 1980, p. 13). A palavra e o traço do pincel desrealizam e subvertem "a representação autoritária, progressiva, monovalente, desvitalizada em que o real tende a fixar-se" (ROSA apud BESSE, 1981, p. 36). Vê-se que Bissier e Ramos Rosa compartilham das mesmas concepções quanto ao processo de criação artística.

Os três últimos versos (v. 13 a 15), terceiro bloco do poema, abordam o que ocorre no intervalo entre os dois campos tratados nos blocos anteriores: "Entre o símbolo e o objecto desenha-se uma flor" (v. 13). Que seria essa flor, que se desenha, mas não se vê? Paz responde: "La imagen es el puente que tiende el deseo entre el hombre y la realidad" (PAZ, 1972, p. 66). A flor entre o símbolo e o objeto é a imagem, ponte e "elemento mediador entre ambos - a palavra [...] e o silêncio" (JÚDICE, 2005, p. 36). Entre a simbolização e a realidade, está a imagem, a criação de sentidos. Ela não está explícita na tela (ou no poema): o que vemos são as linhas do vazio, os traços de têmpera nas felizes miniaturas bissierianas. É pela contemplação dessas linhas, num processo interpretativo, que essa flor se desenhará.

\footnotetext{
${ }^{7}$ Cf. descrição técnica da Composição 9 (Figura 2): “The actually silent composition gains a narrative component by means of rudimentary calligraphic signs, its decryption, however, remains impossible". Disponível em: <http://www.kettererkunst.com/details-e.php?obnr=111001620\&anummer=380>.
} 
Como diz Paul Klee, um dos mestres de Bissier, “a imagem não reproduz o visível; torna-se visível” (KLEE apud GUIMARÃES, 2005, p. 19). Os últimos versos do poema destacam a atividade criadora do espectador/leitor, que vê as linhas do vazio das miniaturas e, a partir delas, constrói imagens outras. O pintor e o poeta separam objeto e palavra do mundo e da linguagem; o espectador e o leitor realizam o processo de recriação, regresso do objeto/palavra ao mundo (cf. PAZ, 1972, p. 38-39).

A pintura de Bissier e a poesia de Ramos Rosa negam à arte o estatuto de "acesso privilegiado à realidade" (HUTCHEON, 1991, p. 202) e renunciam à "ideia convencional de representação" (AMARAL, 2005, p. 49), tomando a imagem - e não a reprodução do mundo - como cerne da criação artística. António Ramos Rosa constrói imagens poéticas a partir do diálogo intertextual com as artes plásticas, trazendo para a arena das palavras, com maestria, o mundo da imagem plástica.

\section{REFERÊNCIAS}

AMARAL, Fernando Pinto do. Melancolia e plenitude na poesia de António Ramos Rosa. In: MENDES, Ana Paula Coutinho (Org.). Poesia do século XX com António Ramos Rosa ao fundo. Porto: Universidade do Porto, 2005. p. 43-52. Disponível em: <http://ler.letras.up.pt/uploads/fiche iros/11514.pdf>. Acesso em: 11 jul. 2016.

BESSE, Maria Graciette. A palavra e o silêncio na poesia de António Ramos Rosa. Colóquio/Letras, Lisboa, n. 81, p. 30-38, maio 1981.

BISSIER, Julius. Composição 9, 1960, têmpera ovo e óleo, 18,3 cm x 23,7 cm. Disponível em: <http://www.kettererkunst.com/details-e.php?obnr=111001620\&anummer=380>. Acesso em: 13 jul. 2014.

. Rondine, 1961, têmpera ovo e óleo, 17 cm x 24 cm. Disponível em: <http://www.nonsolo-arte.com/julius-bissier-watercolors.html>. Acesso em: 14 ago. 2016.

CARLOS, Luís F. Adriano. Recensão a Incisões oblíquas. Colóquio/Letras, n. 103, Lisboa, p. 98-100, maio 1988.

CRUZ, Gastão. António Ramos Rosa: a legitimidade das palavras. In: MENDES, Ana Paula Coutinho (Org.). Poesia do século XX com António Ramos Rosa ao fundo. Porto: Universidade do Porto, 2005. p. 25-30. Disponível em: <http://ler.letras.up.pt /uploads/ficheiros/11514.pdf>. Acesso em: 11 jul. 2016.

GOLDSTEIN, Norma. Versos, sons, ritmos. 7.ed. São Paulo: Ática, 1991.

GUIMARÃES, Fernando. Os lugares da imagem na poesia de António Ramos Rosa. In: MENDES, Ana Paula Coutinho (Org.). Poesia do século XX com António Ramos Rosa ao 
fundo. Porto: Universidade do Porto, 2005. p. 17-22. Disponível em: <http://ler.letras.up.pt/uploads/ficheiro s/11514.pdf>. Acesso em: 11 jul. 2016.

HUTCHEON, Linda. Poética do pós-modernismo: história, teoria, ficção. Trad. de Ricardo Cruz. Rio de Janeiro: Imago, 1991.

JÚDICE, Nuno. A construção do poema em António Ramos Rosa. In: MENDES, Ana Paula Coutinho (org.). Poesia do século XX com António Ramos Rosa ao fundo. Porto: Universidade do Porto, 2005. p. 33-39. Disponível em: <http://ler.letras.up.pt/uploads/ficheiros/11514.pdf>. Acesso em: 11 jul. 2016.

JULIUS BISSIER. Disponível em: <http://eye-likey.blogspot.com.br/2012/01/juliusbissier.html>. Acesso em: 23 jul. 2016. jul. 2016.

Disponível em: <http://www.tate.org.uk/art/artists/julius-bissier-756>. Acesso em: 11

JULIUS HEINRICH BISSIER. Disponível em: <http://www.julius-bissier.com>. Acesso em: 11 jul. 2016.

LOTMAN, Iuri. A estrutura do texto artístico. Tradução de Maria do Carmo Vieira Raposo e Alberto Raposo. Lisboa: Estampa, 1978.

MEXIA, Pedro. O cavalo é sem porquê. In: MENDES, Ana Paula Coutinho (Org.). Poesia do século XX com António Ramos Rosa ao fundo. Porto: Universidade do Porto, 2005. p. 55-65. Disponível em: <http://ler.letras.up.pt/uploads/ficheiros/ 11514.pdf>. Acesso em: 11 jul. 2016.

PAZ, Octavio (1956). El arco y la lira: el poema, la revelación poética, poesía e historia. 3.ed. México: Fondo de Cultura Economica, 1972.

RIFFATERRE, Michael. Compulsory reader response: the intertextual drive. In: WORTON, Michael; STILL, Judith. Intertextuality: theories and practices. Manchester: Manchester University Press, 1990. p. 56-78.

ROSA, António Ramos. Do domínio plástico. Porto: Asa, 2004.

TODOROV, Tzvetan. Simbolismo e interpretação. Tradução de Maria de Santa Cruz. Lisboa: Edições 70, 1980.

WORTON, Michael; STILL, Judith. Introduction. In: practices. Manchester: Manchester University Press, 1990. p. 56-78. Intertextuality: theories and 